\title{
Alcohol use disorder among prisoners in Debre Berhan prison, Ethiopia: a cross-sectional study
}

\author{
Yohannes Gebreegziabhere Haile ${ }^{1,2^{*}}$, Kaleab Berhanu Kebede ${ }^{1}$, Asnake Limenhe ${ }^{2}$, Kassahun Habatmu ${ }^{3}$ and \\ Atalay Alem ${ }^{2}$
}

\begin{abstract}
Background: Several studies reported that history of alcohol use among prisoners is higher than the prevalence in the general population. Criminality is found to be associated with alcohol use disorder (AUD) in previous studies. In Ethiopia, there is limited information on the prevalence and associated factors of AUD among prisoners. Therefore, this study aimed to assess the prevalence and associated factors of AUD among prisoners of Debre Berhan Prison.

Methods: A cross-sectional survey was conducted to assess history of AUD among prisoners at Debre Berhan Prison, before imprisonment. We selected 347 prisoners with a systematic sampling technique and interviewed using Alcohol Use Disorder Identification Test (AUDIT) to screen for AUD in May 2017. Data entry was done using Epi-Data version 3.1 software, and bivariate and multivariate analyses were done using Stata version 13 software. Crude and adjusted odds ratios, with 95\% confidence intervals and $p$-values are reported.

Results: About six out of ten prisoners (59.1\%) had AUD before imprisonment. Factors associated with increased odds of AUD were perception that the current offence is related to using substances ( $A O R=4.2 ; 95 \% \mathrm{Cl}=2.3,7.8$ ), and family history of substance use ( $A O R=8.7 ; 95 \% \mathrm{Cl}=1.7,44.9)$. Being married had lower odds of AUD compared to the unmarried $(\mathrm{AOR}=0.5 ; 95 \% \mathrm{Cl}=0.2,0.9)$.

Conclusion: We found that the prevalence of AUD 1 year before imprisonment in this population is high. AUD is found to be associated with a family history of substance use and perception that the current offence is related to using a substance. We recommend community-based study with different kind of study designs to see the relationship between AUD and crime for planning interventions.
\end{abstract}

Keywords: Substance use, Alcohol use disorder, Prevalence, Associated factors, Prison, Ethiopia

\section{Background}

The burden of mental and substance use disorders is high globally, and it is particularly worse in alcohol-related problems, according to the World Health Organization (WHO), worldwide three million deaths $(5.3 \%$ of all

\footnotetext{
* Correspondence: yohannes36@gmail.com

'Department of Nursing, Debre Berhan University, Debre Berhan, Ethiopia

${ }^{2}$ Department of Psychiatry, College of Health Sciences, Addis Ababa University, Addis Ababa, Ethiopia

Full list of author information is available at the end of the article
}

deaths) every year resulted from harmful use of alcohol [1]. In support of this, the WHO global burden of diseases 2016 report showed that alcohol was the seventh leading risk factor for both deaths and disability-adjusted life years (DALYs) [2]. In terms of year's lost due to disability (YLDs), in 2010 mental and substance use disorders were the leading $(22.9 \%$ of the world YLDs or 175.3 million YLDs) [3]. In the same document, it was reported that about 184 million DALYs worldwide were due to mental and substance use disorders (7.4\% of all the DALYs) and 
ranked 5th among the top 10 causes of DALYs. The WHO global burden of disease 2010 report also showed that $9.6 \%$ of DALYs were due to mental and substance use disorders secondary to alcohol use.

Every year 6.21 of pure alcohol is consumed worldwide per person of age greater than 15 years [4]. In Ethiopia, the consumption of alcohol was reported to be 4.21 per person of age older than 15 years per year, in 2010 [5]. WHO sets a target of reducing the harmful use of alcohol by $10.0 \%$ by the year 2025 [4]; we believe that this may not be achieved without including the prison population as part of a targeted population group for intervention.

According to the international center for prison studies report in 2013, over the last 15 years before 2013, the world population had increased by over $20 \%$, but the world prison population during the same period increased by $25-30 \%$ [6]. The same report disclosed that as of the beginning of October 2013, more than 11 million people in the world were either in prison, in pretrial, or in administrative detention; which translates to 155 people per 100, 000 population. The same report showed that in 2013 there were about 112,361 prisoners in Ethiopia (this is equivalent to 136 prisoners per 100, 000 people) [6].

Several studies have reported that crime and substance use have direct relationship [7-9]. In addition, alcohol use has been reported to be associated with intimate partner violence [10]. One of the reasons why people use substance is to increase their confidence to commit crime [11]. In support of this, one study found that $10 \%$ of homicide offenders claimed that the offense took place while they were under the influence of a substance [12].

Alcohol is among the top five list of drugs abused among prisoners, either in prison or before imprisonment [13-19]. Compared to the general population alcohol use was reported to be twice as common in prisoners [20]. The prevalence of any substance use among prison populations ranged from as low as $20.1 \%$ to as high as $95.5 \%[18,21-24]$. Prevalence ranging from 10.7 to $70.0 \%$ was reported for alcohol use disorder (AUD) [13, 17-19, 21-28]. A systematic review of studies from the United Kingdom reported that 13 to $86 \%$ of prisoners at a different stage of imprisonment (remanded and sentenced) had alcohol dependence or AUD [29]. A 20-year study to see the trended of AUD, from 1985 to 2006, showed an increase in the prevalence of AUD in male prisoners from $41 \%$ in 1985 to $52 \%$ in 2006 [30]. This indicates that the trend of AUD while in prison increases with time.

On the other hand, the prevalence of substance use disorder (SUD) among prisoners before imprisonment was higher than both from use in prison and use in the general population, which may indicate association between crime and substance use. Studies in prisoners have shown that prevalence ranged from 50 to $88 \%$ for general substance use and 13 to $86 \%$ for AUD before imprisonment $[11,12,16,31-45]$. A recent systematic review of about 24 studies from 10 different countries reported prevalence of AUD ranging from 16 to 51\% among newly incarcerated male prisoners, with a pooled prevalence of $26 \%$ [46]. Another systematic review reported prevalence rate of alcohol dependence in prisoners ranging from 18 to $30 \%$ in males and 10 to $24 \%$ in females [47].

When it comes to low-and middle-income countries, there are very few studies on the prevalence of SUD among prisoners. A recent systematic review by Fazel and colleagues [46], reported that only 2 out of 10 studies included in the review were from low- and middleincome countries. Prevalence of 45 and $30 \%$ were reported from those two countries for AUD [46]. When it comes to Africa, very few studies examined SUD among prisoners. One of these is a study from Kenya which reported a prevalence of $65.1 \%$ for AUD [11]. In a Nigerian prison study, a prevalence of $13 \%$ was reported for past history of alcohol abuse [39].

Substance use before imprisonment is reported to be associated with younger age, male sex, urban residence, higher educational status, physical health problem, type of crime committed (property theft, rape, or fraud), seriousness of crime, repeated offence, and presence of depression [11, 40, 48-51]. Prisoners with history of SUD were found to have twice increased risk of suicide attempt compared to those who did not have SUD [13].

In Ethiopia, a systematic review on the epidemiology of alcohol use reported 24 and $44 \%$ pooled prevalence for current and life time alcohol consumption, respectively [52]. None of the included studies in this review had involved prisoners. A study conducted among prisoners in Jimma town who had committed homicide reported a prevalence of $34 \%$ for history of alcohol abuse, and $44 \%$ for history of khat use [12]. However, AUD was not included in that study. Another study from the same setting also had reported a $40 \%$ prevalence for AUD among prisoners [53]. Those studies were conducted in an area which has a different context from Debre Berhan where alcohol production and use is said to be commoner. While, khat (an amphetamine-like psychoactive substance) use is commoner in Jimma.

Huge unmet need, in terms of mental health services for prisoners, was reported in a Nigerian study [54]. Hence, this study can help different stakeholders such as the police, the health sector, and other governmental and non-governmental organizations in designing and implementing strategies to reduce alcohol-related problems including criminality and meet the needs of prisoners through evidence-based interventions. Therefore, 
this study aimed to examine the prevalence and associated factors of AUD among prisoners 1 year before imprisonment in Debre Berhan Prison (DBP).

\section{Methods}

\section{Study setting and period}

We conducted the study in May 2017, in Debre Berhan, a zonal town of the Amhara Regional State, located 130 $\mathrm{km}$ North-East of Addis Ababa, the capital city of Ethiopia [55]. It lies at an altitude of $2830 \mathrm{~m}$ above sea level and its annual temperature ranges from $10 \mathrm{C}^{0}$ to $28 \mathrm{C}^{0}$ [56]. In 2015, Debre Berhan town had a population of 102,100 [57].

According to administrative office of the prison, DBP was established in 1941 with around 65 prisoners in an old building. Now the prison has moved to a new building starting 28th September 2015 with 1582 prisoners. In this prison, there were 1933 eligible individuals for our study during the study period. Prisoners get mental health services from Debre Berhan referral hospital, and the prison administration covers the costs for their health services.

\section{Study design and sampling}

We conducted a cross-sectional study among male prisoners in the said prison. Single proportion formula with assumption of $44 \%$ prevalence based on the report from Jimma prison study in Ethiopia on SUD [12], 5\% point margin of error, $95 \%$ confidence interval, and 10\% nonresponse rate was used to determine the sample size for the study. Since the total population of the study was less than $10,000(N=1933)$, we applied correction formula (i.e. $\mathrm{nf}=\mathrm{n} /(1+\mathrm{n} / \mathrm{N}))$. Using the above formula and assumptions, the final sample size was 347 .

We included all male convicted prisoners who were willing to take part in the study and who had stayed in the prison for 5 years or less to minimize recall bias. We excluded female prisoners from this study because there were only 19 of them as it would be difficult to generalize from such small number of respondents.

We used a systematic sampling method to select study participants. Taking the 1933 eligible prisoners as a sampling frame we calculated the " $K$ " value. Our calculated sample size $(n=347)$ gave us a "K" value of six. We obtained prisoners' list from the attendance sheet and we chose one prisoner from the list (the sampling frame) randomly, using the lottery method of selection. Then, we contacted every $6^{\text {th }}$ prisoner in the list. When we encountered unwillingness to take part in the study, we replaced that participant with the next prisoner from the attendance list. For privacy purpose, we used codes rather than names or other identifiers during data collection. Interviews were conducted in a private room within the prison compound.

\section{Variables}

The outcome variable of this study was AUD, and explanatory variables were socio-demographic factors such as age, occupation, income, religion, and residence; social factors such as physical separation from parents during childhood, experience of history of abuse, satisfaction in life, physical and mental health status, living condition, and family history of substance use. Crime-related information such as year of imprisonment, the reason for imprisonment, previous history of imprisonment, and perception of the relationship between current offence; and substance use history were also collected.

\section{Measures}

\section{Assessment of socio-demographic characteristics}

Socio-demographic characteristics of the participants were assessed using a structured questionnaire, developed by the researchers, which has 10 items.

\section{Assessment of crime-related factors}

Criminal background was assessed using a structured questionnaire, developed by the researchers which has six items.

\section{Assessment of social factors}

Other social factors such as childhood abuse were assessed using a structured questionnaire, developed by the researchers, which has 15 items.

\section{Assessment of alcohol use disorder}

We assessed AUD using WHO's Alcohol Use Disorder Identification Test (AUDIT) questionnaire, which has 10 items with four response categories. The total score of AUDIT ranges from 0 to 40. At cut-off point of eight, the tool has shown on average $90 \%$ sensitivity and $80 \%$ specificity in many countries [58]. AUDIT is a wellevaluated measure where systematic reviews reported remarkable reliability and validity in terms of test-retest reliably, internal consistency, and criterion validity [59, 60]. In this study those who scored eight and above were considered as having AUD. Scores 8 to 15 were considered as indicators of harmful drinking, scores 16 to 19 as hazardous drinking, and scores of $20+$ as dependency.

To determine a standard 'drink', we converted local drinks to grams of pure alcohol, and then we specified the amount of pure alcohol per each local drink and local unit of measure. The level of alcohol content of local drinks was taken from a previous work by Fekadu and colleagues [61]. We considered $10 \mathrm{~g}$ of pure alcohol as one standard unit of drink. The details of the 
calculation can be found from the principal investigator upon request. AUDIT is reported to be suitable for the prison population in non-English speaking communities [62]. The Amharic version of AUDIT was adapted and used in Ethiopia previously to assess AUD in many published works [53, 63-66]. This tool assesses a one-year prevalence of AUD. Since it is not allowed to drink alcohol in DBP, it was not possible to determine current prevalence of AUD. Therefore, we assessed a one-year prevalence before imprisonment.

\section{Data collection procedures}

We used the adapted Amharic version of AUDIT in this study as in the previous studies. For the exposure variables, we developed and used questionnaires in Amharic, the official language of the country spoken in the study area.

We conducted a pre-test in 17 pre-trial detainees (5\% of our main sample) in Debre Berhan police custody, and we made correction on ambiguous items in our tools before the actual data collection. Five trained graduating class BSc nursing students collected data through a face to face interview. A mental health professional supervised the data collection process.

\section{Data analysis}

We entered the data using EPI-data version 3.1 program and analyzed it using Stata version 13 . The data are available and can be supplemented in commadelimited (".csv) dataset format, up on request. We checked the data for consistency, outliers, and missing values. We also conducted a reliability analysis of the outcome measure. We used both univariate and multivariate binary logistic regression analyses to identify factors significantly associated with AUD. In the multivariate model, we included variables with $p$ value $<0.05$ as independently associated with the outcome variable. We measured the strength of association between the outcome and the exposure variables using odds ratio (OR) with 95\% confidence interval $(\mathrm{CI})$.

\section{Results}

\section{Socio-demographic characteristics of participants}

A total of 347 male prisoners took part in the study. The response rate was $100 \%(n=347)$. The mean age (in years) of the respondents was 27.76; SD \pm 11.4 years (Range: 16-82 years). About one-third of the participants (29.1\%) were in the age range of $16-20$ years. The mean age (in years) of the participants at the time of imprisonment was 26.22; $\mathrm{SD}+11.3$ years. About half of the participants $(48.1 \%)$ had primary level education before imprisonment. The median monthly income (in
Ethiopian Birr (ETB)) of the participants before imprisonment was 1500 Ethiopian Birr (ETB) $(1 \mathrm{USD}=23.09$ ETB, during the period of data collection). The vast majority of the participants were from Amhara Ethnic group (93.4\%), and followers of Orthodox Christianity (93.1\%). About three out of five (59.7\%) were single, and a little more than half $(51.6 \%)$ of the study participants were rural residents (Table 1).

Social factors, and the crime history of the participants As showed in Table 2, a little more than half of the participants $(52.7 \%)$ stayed in prison for less than 1 year. The reason for imprisonment for almost one-third (29.7\%) of the participants was committing homicide. For a vast majority of the respondents $(95.4 \%)$ this is their first imprisonment. Over a third (34.6\%) of the participants reported that they committed the crime under the influence of a substance (Table 2).

More than one-fifth of the participants $(22.2 \%)$ reported that they got separated from their families physically when they were small children; while $11.5 \%$ reported experiencing childhood abuse. Only $7.8 \%$ of the participants reported that their family had a history of substance use (khat chewing accounting for $63.0 \%$ of substances used). One-fifth (19.9\%) of the participants used to live alone before the current imprisonment. The majority $(83.0 \%)$ reported that they had no problem to meet their daily needs or the needs of their families. More than two-thirds of the prisoners rated their overall level of satisfaction in life as good and very good (36.6 and $35.7 \%$, respectively). Most of the study participants reported that they had no major physical or mental illness before imprisonment (90.0, and 95.1\%, respectively) (Table 3).

\section{Reliability of the outcome measure}

Although the instrument used to assess the outcome variable in this study is a standard measure, we conducted internal consistency reliability analysis and found very good internal consistency of the instrument $(\alpha=0.791)$. Itemtotal correlation for items 2 and 3 was near to 0.3; while for the reaming items it was above 0.3. Removing any of the items did not improve the overall internal consistency of the instrument significantly. Therefore, we used all the items of AUDIT in our analyses.

\section{Prevalence of alcohol use disorder}

At a cutoff point of eight, 59.1\% $(n=205),(95 \%$, CI (53.8-64.2\%)) of the respondents had AUD 1 year before their imprisonment. Two-third (66.3\%) of those with AUD were harmful drinkers (Table 4). 
Table 1 Socio-demographic characteristics of participants

\begin{tabular}{|c|c|c|c|}
\hline Variable & Response categories & Frequency $(n=347)$ & Percentage \\
\hline \multirow[t]{4}{*}{ Age } & $<=20$ & 101 & 29.1 \\
\hline & $21-24$ & 76 & 21.9 \\
\hline & $25-29$ & 76 & 21.9 \\
\hline & $\geq 30$ & 94 & 27.1 \\
\hline \multirow[t]{2}{*}{ Marital status } & Unmarried $^{c}$ & 216 & 62.2 \\
\hline & Married & 131 & 37.8 \\
\hline \multirow[t]{4}{*}{ Educational status } & Unable to read and write & 93 & 26.8 \\
\hline & Primary education & 167 & 48.1 \\
\hline & Secondary education & 65 & 18.7 \\
\hline & Territory education & 22 & 6.3 \\
\hline \multirow[t]{6}{*}{ Occupational status before imprisonment } & Government employee & 20 & 5.8 \\
\hline & Personal business & 83 & 23.9 \\
\hline & Daily labourer & 27 & 7.8 \\
\hline & Student & 32 & 9.2 \\
\hline & Farmer & 144 & 41.5 \\
\hline & Other $^{\mathrm{b}}$ & 41 & 11.8 \\
\hline \multirow[t]{2}{*}{ Ethnicity } & Amhara & 324 & 93.4 \\
\hline & Other ${ }^{a}$ & 23 & 6.6 \\
\hline \multirow[t]{2}{*}{ Religion } & Orthodox Christian & 323 & 93.1 \\
\hline & Other $^{d}$ & 24 & 6.9 \\
\hline \multirow[t]{5}{*}{ Frequency of church/mosque visit before imprisonment } & Daily & 67 & 19.3 \\
\hline & 2-3 times per week & 32 & 9.2 \\
\hline & Once a week & 154 & 44.4 \\
\hline & Less than weekly & 61 & 17.6 \\
\hline & Never & 33 & 9.5 \\
\hline \multirow[t]{2}{*}{ Residence } & Urban & 168 & 48.4 \\
\hline & Rural & 179 & 51.6 \\
\hline
\end{tabular}

a Oromo, Tigray, Afar, and Gurage. ${ }^{\mathrm{b}} \mathrm{Car}$ driver, assistant driver, and a broker. ${ }^{\mathrm{c}}$ Single, divorced, separated, and widowed. ${ }^{\mathrm{d}}$ Protestant and Muslim

Table 2 Index crime committed by participants

\begin{tabular}{|c|c|c|c|}
\hline Variable & Response categories & Frequency $(n=347)$ & $\%$ \\
\hline \multirow[t]{5}{*}{ Index offense } & Homicide & 103 & 29.7 \\
\hline & Theft and robbery & 67 & 19.3 \\
\hline & Rape & 41 & 11.8 \\
\hline & Fight & 91 & 26.2 \\
\hline & Others $^{a}$ & 45 & 13.0 \\
\hline \multirow[t]{2}{*}{ Length of stay in prison } & $\leq 12$ months & 183 & 52.7 \\
\hline & $>12$ months and $<5$ years & 164 & 47.3 \\
\hline \multirow[t]{2}{*}{ Prior history of imprisonment } & Yes & 16 & 4.6 \\
\hline & No & 331 & 95.4 \\
\hline \multirow[t]{2}{*}{ Perception that the crime was related to substance use } & Yes & 120 & 34.6 \\
\hline & No & 227 & 65.4 \\
\hline
\end{tabular}

${ }^{a}$ Road traffic accident (RTA), protection of a person who committed crime, smuggling, human trafficking, abduction, corruption, and tax evasion 
Table 3 Social-related characteristics of participants

\begin{tabular}{|c|c|c|c|}
\hline Variable & Response Categories & Frequency $(n=347)$ & Percentage \\
\hline \multirow[t]{2}{*}{ Separation from parents during Childhood } & Yes & 77 & 22.2 \\
\hline & No & 270 & 77.8 \\
\hline \multirow[t]{2}{*}{ Childhood abuse } & Yes & 40 & 11.5 \\
\hline & No & 307 & 88.5 \\
\hline \multirow[t]{2}{*}{ Family history of substance use } & Yes & 27 & 7.8 \\
\hline & No & 320 & 92.2 \\
\hline \multirow[t]{3}{*}{ Living arrangement before imprisonment } & Alone & 69 & 19.9 \\
\hline & With friend & 36 & 10.4 \\
\hline & With family & 242 & 69.7 \\
\hline \multirow[t]{5}{*}{ Satisfaction with life before imprisonment } & Very poor & 13 & 3.8 \\
\hline & Poor & 25 & 7.2 \\
\hline & Neutral & 58 & 16.7 \\
\hline & Good & 127 & 36.6 \\
\hline & Very good & 124 & 35.7 \\
\hline \multirow[t]{2}{*}{ Struggling to meet daily needs before imprisonment } & Yes & 59 & 17.0 \\
\hline & No & 288 & 83.0 \\
\hline \multirow[t]{2}{*}{ Major physical illness before imprisonment } & Yes & 34 & 10.0 \\
\hline & No & 306 & 90.0 \\
\hline \multirow[t]{2}{*}{ Major mental illness before imprisonment } & Yes & 17 & 4.9 \\
\hline & No & 329 & 95.1 \\
\hline
\end{tabular}

\section{Factors associated with alcohol use disorder}

After controlling for the effects of potential confounding variables, being married (Wald chi-square $=5.86$; $\mathrm{df}=1$; $\mathrm{AOR}=0.5,95 \% \mathrm{CI}=0.2-0.9 ; p=0.015)$, and the index offence of others category (which included road traffic accident (RTA), smuggling goods, participating in human trafficking, etc.) (Wald chi-square $=4.84 ; \mathrm{df}=1 ; \mathrm{AOR}=$ 2.6, 95\% CI $=1.1-5.9 ; p=0.028$ ) were significantly associated with AUD. The perception that index offence was alcohol-related (Wald chi-square $=21.72 ; \mathrm{df}=1 ; \mathrm{AOR}=$ $4.2,95 \% \mathrm{CI}=2.3-7.8 ; p<0.001)$, and a family history of substance use (Wald chi-square $=6.71 ; \mathrm{df}=1 ; \mathrm{AOR}=8.7$, 95\% CI $=1.7-44.9 ; p=0.009$ ) were also significantly associated with AUD. Whereas, increased age was not associated with AUD but the $p$-value was close to level of significance (Wald chi-square $=3.72 ; \mathrm{df}=1 ; \mathrm{AOR}=2.3$, 95\% CI $=1.0-5.3 ; p=0.054$ ) (Table 5).
The odds of those who were married to be cases of AUD were $50 \%$ less compared to unmarried participants (Wald chi-square $=5.86 ; \mathrm{df}=1 ; \mathrm{AOR}=0.5,95 \% \mathrm{CI}=$ $0.2-0.9 ; p=0.015)$. The odds of those who were imprisoned because of RTA, contraband, corruption, etc. in having AUD were nearly 3 times higher than those imprisoned because of homicide (Wald chisquare $=4.84 ; \mathrm{df}=1 ; \mathrm{AOR}=2.6,95 \% \mathrm{CI}=1.1-5.9 ; p=$ 0.028). Furthermore, the odds of prisoners who perceive that their current offence was related to substance use in having AUD were about 4 times higher than those who did not think that substance use were not related to their current offence (Wald chisquare $=21.72 ; \quad \mathrm{df}=1 ; \quad \mathrm{AOR}=4.2, \quad 95 \% \quad \mathrm{CI}=2.3-7.8$; $p<0.001)$. The odds of those who had family history of substance use in having AUD were 9 times higher compared to those who did not report family history

Table 4 One-year prevalence and severity of alcohol use disorder

\begin{tabular}{llll}
\hline Variable & Response categories & Frequency $(n=347)$ & $\%$ \\
\hline Alcohol use disorder & Yes & 205 & 59.1 \\
Severity of alcohol use disorder & No & 142 & 40.9 \\
& Harmful drinking (8-15) & 136 & 66.3 \\
& Hazardous drinking (16-19) & 27 & 13.2 \\
& Dependence (20+) & 42 & 20.5 \\
\hline
\end{tabular}


Table 5 Sociodemographic, personal, and criminal related factors associated with alcohol use disorder

\begin{tabular}{|c|c|c|c|c|c|}
\hline \multirow[t]{2}{*}{ Variable } & \multirow[t]{2}{*}{ Response category } & \multicolumn{2}{|c|}{ AUD caseness } & \multirow[t]{2}{*}{ COR $(95 \% \mathrm{Cl})$} & \multirow[t]{2}{*}{ AOR $(95 \% \mathrm{Cl})$} \\
\hline & & No (\%) & Yes (\%) & & \\
\hline \multirow[t]{4}{*}{ Age } & $\leq 20$ & $38(37.6)$ & $63(62.4)$ & 1.0 & 1.0 \\
\hline & $21-24$ & $36(47.4)$ & $40(52.6)$ & $0.7(0.4,1.2)$ & $0.6(0.3,1.3)$ \\
\hline & $25-29$ & $34(44.7)$ & $42(55.3)$ & $0.7(0.4,1.4)$ & $1.1(0.5,2.4)$ \\
\hline & $\geq 30$ & $34(36.2 \%)$ & $60(63.8 \%)$ & $1.1(0.6,1.9)$ & $2.3(1.0,5.3)$ \\
\hline \multirow[t]{2}{*}{ Marital status } & Unmarried $^{a}$ & $81(37.5)$ & $135(62.5)$ & 1.0 & 1.0 \\
\hline & Married & $61(46.6)$ & $70(53.4)$ & $0.7(0.4,1.1)$ & $0.46(0.2,0.9)$ \\
\hline \multirow[t]{5}{*}{ Frequency of worship } & Daily & $30(44.8)$ & $37(55.2)$ & $0.8(0.4,1.4)$ & $0.6(0.3,1.1)$ \\
\hline & 2-3 times per week & $15(46.9)$ & $17(53.1)$ & $0.7(0.3,1.6)$ & $0.6(0.2,1.4)$ \\
\hline & Once a week & 61 (39.6) & $93(60.4)$ & 1.0 & 1.0 \\
\hline & Less than weekly & $29(47.5)$ & $32(52.5)$ & $0.7(0.4,1.3)$ & $0.6(0.3,1.2)$ \\
\hline & Never & 7 (21.21\%) & $26(78.79 \%)$ & $2.43(1.00,5.96)$ & $1.38(0.49,3.88)$ \\
\hline \multirow[t]{2}{*}{ Residence } & Urban & $60(35.7)$ & $108(64.3)$ & $1.52(1.0,2.3)$ & $1.23(0.7,2.2)$ \\
\hline & Rural & $82(45.8)$ & $97(54.2)$ & 1.0 & 1.0 \\
\hline \multirow[t]{5}{*}{ Index offense } & Homicidal & $54(52.4)$ & $49(47.6)$ & 1.0 & 1.0 \\
\hline & Stealing \& Robbery & $20(29.8)$ & $47(70.9)$ & $2.59(1.4,5.0)$ & $2.3(1.0,5.2)$ \\
\hline & Rape & 15 (36.6) & $26(63.4)$ & $1.9(0.9,4.0)$ & $1.1(0.4,2.8)$ \\
\hline & Conflict & 36 (39.6) & $55(60.4)$ & $1.7(1.0,3.0)$ & $1.7(0.9,3.4)$ \\
\hline & Other ${ }^{b}$ & $17(37.8)$ & $28(62.2)$ & $1.8(0.9,3.7)$ & $2.6(1.1,5.9)$ \\
\hline \multirow[t]{2}{*}{ History of imprisonment } & Yes & $2(12.5)$ & $14(87.5)$ & $5.1(1.2,22.9)$ & $4.5(0.9,23.7)$ \\
\hline & No & $140(42.3)$ & $191(57.7)$ & 1.0 & 1.0 \\
\hline \multirow[t]{2}{*}{ Substance use for crime } & Yes & $23(19.2)$ & $97(80.8)$ & $4.6(2.8,7.8)$ & $4.2(2.3,7.8)$ \\
\hline & No & $119(52.4)$ & $108(47.6)$ & 1.0 & 1.0 \\
\hline \multirow[t]{2}{*}{ Childhood separation } & Yes & $18(23.4)$ & $59(76.6)$ & $2.8(1.6,5.0)$ & $1.8(0.9,3.6)$ \\
\hline & No & $124(45.9)$ & $146(54.1)$ & 1.0 & 1.0 \\
\hline \multirow[t]{2}{*}{ Childhood abuse } & Yes & $6(15.0)$ & $34(85.0)$ & $4.5(1.8,11.0)$ & $1.9(0.7,5.6)$ \\
\hline & No & $136(44.3)$ & $171(55.7)$ & 1.0 & 1.0 \\
\hline \multirow[t]{2}{*}{ Family hx of substance use } & Yes & $2(7.4)$ & $25(92.6)$ & $9.7(2.3,41.7)$ & $8.7(1.7,44.9)$ \\
\hline & No & $140(43.8)$ & $180(56.2)$ & 1.0 & 1.0 \\
\hline \multirow[t]{3}{*}{ Living status } & Alone & $25(36.2)$ & $44(63.8)$ & $1.4(0.8,2.5)$ & $1.0(0.5,2.1)$ \\
\hline & With friend & $9(25.0)$ & $27(75.0)$ & $2.4(1.1,5.4)$ & $2.3(0.9,6.0)$ \\
\hline & With family & $108(44.6)$ & $134(55.4)$ & 1.0 & 1.0 \\
\hline \multirow[t]{5}{*}{ Satisfaction in life } & Very poor & $4(30.8)$ & $9(69.2)$ & $1.6(0.5,5.5)$ & $0.6(0.1,3.0)$ \\
\hline & Poor & $7(28.0 \%)$ & $18(72.0 \%)$ & $1.8(0.7,4.7)$ & $1.2(0.4,3.4)$ \\
\hline & Neutral & $23(39.7 \%)$ & $35(60.3)$ & $1.1(0.6,2.0)$ & $0.8(0.4,1.6)$ \\
\hline & Good & $53(41.7)$ & $74(58.3)$ & 1.0 & 1.0 \\
\hline & Very good & $55(44.4)$ & $69(55.6)$ & $0.9(0.5,1.5)$ & $0.6(0.4,1.2)$ \\
\hline \multirow[t]{2}{*}{ Struggle to meet needs } & Yes & $17(28.8)$ & $42(71.2)$ & $1.9(1.0,3.5)$ & $1.4(0.6,2.9)$ \\
\hline & No & $125(43.4)$ & $163(56.6)$ & 1.0 & 1.0 \\
\hline
\end{tabular}

Abbreviations: AOR Adjusted odds ratio, AUD Alcohol use disorder, $C I$ Confidence interval, COR Crude odds ratio, $h x$ History Bold is for variables with $p$-value of $<0.05$

${ }^{a}$ Single, divorced, separated, and widowed. ${ }^{b}$ road traffic accident, protection of a person who committed a crime, smuggling, illegal person transfer, abduction, corruption, and cheating 
of substance use (Wald chi-square $=6.71 ; \mathrm{df}=1$; $\mathrm{AOR}=8.7,95 \% \mathrm{CI}=1.7-44.9 ; p=0.009)$ (Table 5).

\section{Discussion}

This study found that around six out of ten prisoners (59.1\%) had AUD 1 year before imprisonment. This finding is consistent with a study conducted among prisoners in England, where $63.0 \%$ of male prisoners were found to have AUD [35]. On the other hand, our study showed a much higher prevalence compared to many of the previous reports from different parts of the world which reported prevalence rates ranging from 13.7 to 51.0\% [16, 20, 31-33, 38, 40, 41, 43, 46, 47]. Our finding is also higher compared to a previous prison based studies in Ethiopia which reported a 34.0\% [12], and 40.1\% [53] prevalence for alcohol use and AUD, respectively. Our finding is also much higher compared to the results of a meta-analysis on the epidemiology of alcohol use in Ethiopia which reported a $24 \%$ pooled prevalence of current use [52]. We had expected that the prevalence of AUD in our study would be lower than those previous findings of use and abuse which one would think are commoner and less problematic compared to AUD. The possible explanation for this finding may be that production and usage of both local and industrially manufactured alcoholic drinks is higher in Debre Berhan compared to those places where other studies were conducted. Debre Berhan is much colder in its weather than those other places and it is also culturally acceptable to drink alcohol to warm up and overcome the effects of the freezing weather. Furthermore, majority of the participants in this study were Orthodox-Christian followers in which drinking alcohol is not prohibited by the religion. On the other hand, the prevalence of AUD in our study is lower than some of the previous studies which reported prevalence ranging from 69.3 to $73.0 \%$ [11, 34, 42]. This variation may be due to several reasons, including differences in socio-cultural, economic, and living conditions. The difference in methodology and measures used might also have contributed to the difference in the findings.

In this study the odds of those who were unmarried were two times higher to be cases of AUD compared to married prisoners. Previous population-based studies have found that AUD is associated with being unmarried [67-70]. The possible explanation for this finding may be that married life is said to bring a more stable lifestyle and responsibility for the family which may not allow people to spend their income on drinking alcohol. Once they are married, they may not have the financial ability to meet the needs of their family as well as for the drink.

The increased association between AUD and the type of crime committed in this study is also similar to previous studies which found that alcohol use is associated with type of crime committed such as property crime $[27,40]$ and rape [51]. The higher association between AUD and participants perception that their current offense was related to substance use may have similarity with a findings that reported association between substance and crime; and intoxication and crime $[9,45,50]$.

Increased association between AUD and family history of substance use seen in this study is consistent with other reports from general population studies [70-72]. This can possibly be explained by genetic and environmental predispositions of the participants which has been well described in the literature. Substance use is a behaviour that one can learn from his/her exposure to family or community environment that commonly use or have appreciation for substance use.

To our knowledge, this study is one of the very few studies in the Ethiopian prisoners to investigate the prevalence and associated factors of alcohol related problems using a standardized instrument. Nevertheless, readers need to consider the following limitations while interpreting the findings. First, we conducted the study only among male prisoners because there were only 19 female prisoners during the study period. Second, there might be recall bias, because participants were asked about their experience with alcohol drinking 1 year before they were imprisoned. The other limitation of the study is social desirability bias. Respondents might have undermined or increased the amount of alcohol consumption they have reported as data collection was done using interview method. Finally, it is likely that Type I error may have been introduced while performing bivariate analyses due to multiple testing.

This study has implication to reduce AUD in the community and prevent its adverse effects such as committing crime and for planning appropriate intervention for people with this problem in the prisons.

\section{Conclusions}

In this study we found that prevalence of AUD 1 year before imprisonment to be very high. More than one-third (34.6\%) of the prisoners reported that they committed the current crime under the influence of a substance, and this is significantly associated with AUD. This suggests that substance use may increase the risk of criminality. However, this may not be necessarily true and one cannot establish such conclusion from a cross-sectional study. It would be more appropriate to conduct a follow-up study which allows us to establish the temporal relationship between substance use and criminality.

Being not married before imprisonment; type of index crime such as RTA, contraband, abduction, and others; perceiving that substance use is related to the current offence; and having a family history of substance use were significantly associated with AUD. These findings 
call for appropriate actions such as creating awareness about consequences of AUD, employing AUD prevention strategies, providing early detection and intervention services, and making AUD treatment available and accessible both in the community and in the prison.

Therefore, a collaborative action needs to be taken by different stakeholders (the police, the health sector, and other government and non-governmental organizations), on the prevention and treatment of AUD in the community and in the prison population. Since there is lack of research on AUD and crime in Ethiopia, we recommend future studies on the subject matter.

\section{Abbreviations \\ AOR: Adjusted odds ratio; AUD: Alcohol use disorder; AUDIT: Alcohol use disorder identification test; Cl: Confidence interval; DALYs: Disability-adjusted life years; DBP: Debre Berhan Prison; OR: Odds ratio; RTA: Road traffic accident; SUD: Substance use disorder; WHO: World Health Organization; YLDs: Year's lost due to disability}

\section{Acknowledgements}

We would like to thank Admkew Tesfa, Betelhem Wondosen, Efrata Edaylalu, and Hermela Taye for their genuine help, especially during the data collection and data entry of this study. Our special thanks go to Debre Berhan Prison administrators and prisoners who gave us support and information. We also would like to thank Mr. Tesfa Dejene and Dr. Helen Jack for their valuable comments and help during analysis and write-up phase of the study.

Finally, we would like to thank AMARl, because part of this work was supported by the DELTAS Africa Initiative [DEL-15-01] through the first author (YG). The DELTAS Africa Initiative is an independent funding scheme of the African Academy of Sciences (AAS)'s Alliance for Accelerating Excellence in Science in Africa (AESA) and supported by the New Partnership for Africa's Development Planning and Coordinating Agency (NEPAD Agency) with funding from the Wellcome Trust [DEL-15-01] and the UK government. The views expressed in this publication are those of the author(s) and not necessarily those of AAS, NEPAD Agency, WellcomeTrust or the UK government.

\section{Authors' contributions}

$\mathrm{KB}$ and $\mathrm{YG}$ conceived and designed the study. $\mathrm{YG}$ and $\mathrm{KB}$ analyzed the data. $Y G, K B, A L, K H$, and $A A$ drafted the manuscript. All the authors read the manuscript several times and have given their final approval for publication.

\section{Funding}

This research was supported by Debre Berhan University. The Research Directorate of the College of Health Sciences monitored and evaluated the progress of the research. The funder has no role in the interpretation of findings and decision for publication.

\section{Availability of data and materials}

The data used for this study can be made available with a reasonable request from the corresponding author.

\section{Ethics approval and consent to participate}

We obtained ethical approval from the Ethical Review Committee of the College of Health Sciences, Debre Berhan University. We obtained further permission to conduct the research from the respective prison office. Written informed consent was obtained from each participant. We kept privacy and confidentiality by replacing all names with codes and by keeping all the data we collected in a locked bag.

\section{Consent for publication}

Not applicable.

\section{Competing interests}

The authors declare that they have no conflict of interest.

\section{Author details}

'Department of Nursing, Debre Berhan University, Debre Berhan, Ethiopia. ${ }^{2}$ Department of Psychiatry, College of Health Sciences, Addis Ababa University, Addis Ababa, Ethiopia. ${ }^{3}$ School of Psychology, College of Education and Behavioral Studies, Addis Ababa University, Addis Ababa, Ethiopia.

Received: 6 November 2019 Accepted: 23 March 2020

Published online: 03 April 2020

\section{References}

1. WHO. Alcohol fact sheet 2018 [cited 2019 December 12]. Available from: https://www.who.int/news-room/fact-sheets/detail/alcohol.

2. Collaborators GBDA. Alcohol use and burden for 195 countries and territories, 1990-2016: a systematic analysis for the Global Burden of Disease Study 2016. Lancet (London, England). 2018;392(10152):1015-35.

3. Whiteford HA, Degenhardt L, Rehm J, Baxter AJ, Ferrari AJ, Erskine HE, et al. Global burden of disease attributable to mental and substance use disorders: findings from the Global Burden of Disease Study 2010. Lancet (London, England). 2013;382(9904):1575-86.

4. Organization WH. Global status report on alcohol and health World Health Organization, 20 avenue Appia, 1211 Geneva 27, Switzerland; 2014.

5. Organization WH. Country profiles on alcohol consumption, health consequence, and policy 2014.

6. Studies ICfP. World Prison Population List. Victoria Charity Centre 11 Belgrave Road London SW1V 1RB United Kingdom; 2013.

7. Yarvis RM. Patterns of substance abuse and intoxication among murderers. Bull Am Acad Psychiatry Law. 1994;22(1):133-44.

8. Popovici I, Homer JF, Fang H, French MT. Alcohol use and crime: findings from a longitudinal sample of U.S. adolescents and young adults. Alcohol Clin Exp Res. 2012;36(3):532-43.

9. Poldrugo F. Alcohol and criminal behaviour. Alcohol Alcoholism (Oxford, Oxfordshire). 1998;33(1):12-5.

10. Salom CL, Williams GM, Najman JM, Alati R. Substance use and mental health disorders are linked to different forms of intimate partner violence victimisation. Drug Alcohol Depend. 2015;151:121-7.

11. Kinyanjui DW, Atwoli L. Substance use among inmates at the Eldoret prison in Western Kenya. BMC Psychiatry. 2013;13:53.

12. Audu M, Tesfaye M, Gurmu S, Mela M. Lifetime prevalence of substance abuse and mental distress among homicide offenders in Jimma Prison, Ethiopia. 2004.

13. Gates ML, Turney A, Ferguson E, Walker V, Staples-Horne M. Associations among Substance Use, Mental Health Disorders, and Self-Harm in a Prison Population: Examining Group Risk for Suicide Attempt. International journal of environmental research and public health. 2017;14(3):317.

14. Dissabandara LO, Dias SR, Dodd PR, Stadlin A. Patterns of substance use in male incarcerated drug users in Sri Lanka. Drug Alcohol Review. 2009;28(6): $600-7$.

15. Holmwood C, Marriott M, Humeniuk R. Substance use patterns in newly admitted male and female south Australian prisoners using the WHOASSIST (alcohol, smoking and substance involvement screening test). Int J Prison Health. 2008:4(4):198-207.

16. Rao R, Mandal P, Gupta R, Ramshankar P, Mishra A, Ambekar A, et al. Factors affecting drug use during incarceration: a cross-sectional study of opioiddependent persons from India. J Subst Abus Treat. 2016:61:13-7.

17. Proctor SL. Substance use disorder prevalence among female state prison inmates. Am J Drug Alcohol Abuse. 2012;38(4):278-85.

18. Casares-Lopez MJ, Gonzalez-Menendez A, Bobes-Bascaran MT, Secades R, Martinez-Cordero A, Bobes J. Need for the assessment of dual diagnosis in prisons. Adicciones. 2011;23(1):37-44.

19. Amdzaranda PA, Fatoye FO, Oyebanji AO, Ogunro AS, Fatoye GK. Factors associated with psychoactive substance use among a sample of prison inmates in Ilesa, Nigeria. Nigerian Postgraduate Med J. 2009;16(2):109-14.

20. Bushnell JA, Bakker LW. Substance use disorders among men in prison: a New Zealand study. Australian New Zealand J Psychiatry. 1997;31(4):577-81.

21. Sanchez FC, Fearn N, Vaughn MG. Prevalence and correlates of in-prison substance use among incarcerated women in Spain. J Ethn Subst Abus. 2017:1-19.

22. Khalooei A, Mashayekhi-Dowlatabad M, Rajabalipour MR, Iranpour A. Pattern of substance use and related factors in male prisoners. Addiction Health. 2016;8(4):227-34. 
23. Abdulmalik JO, Adedokun BO, Baiyewu OO. Prevalence and correlates of mental health problems among awaiting trial inmates in a prison facility in Ibadan, Nigeria. Afr J Med Med Sci. 2014;43(Suppl 1):193-9.

24. Butler T, Indig D, Allnutt S, Mamoon H. Co-occurring mental illness and substance use disorder among Australian prisoners. Drug Alcohol Review. 2011;30(2):188-94.

25. Baltieri DA. Predictors of drug use in prison among women convicted of violent crimes. Criminal Behaviour Mental Health 2014;24(2):113-28.

26. Lintonen TP, Vartiainen H, Aarnio J, Hakamaki S, Viitanen P, Wuolijoki T, et al Drug use among prisoners: by any definition, it's a big problem. Substance Use Misuse. 2011;46(4):440-51.

27. Lukasiewicz M, Falissard B, Michel L, Neveu X, Reynaud M, Gasquet I. Prevalence and factors associated with alcohol and drug-related disorders in prison: a French national study. Substance abuse treatment, prevention, and policy. 2007;2:1.

28. Sarlon E, Duburcq A, Neveu X, Morvan-Duru E, Tremblay R, Rouillon F, et al. Imprisonment, alcohol dependence and risk of delusional disorder: a crosssectional study. Revue d'epidemiologie et de sante publique. 2012;60(3): 197-203.

29. Newbury-Birch D, McGovern R, Birch J, O'Neill G, Kaner H, Sondhi A, et al. A rapid systematic review of what we know about alcohol use disorders and brief interventions in the criminal justice system. Int J Prison Health. 2016; 12(1):57-70.

30. Lintonen T, Obstbaum Y, Aarnio J, von Gruenewaldt V, Hakamaki S, Kaariainen J, et al. The changing picture of substance abuse problems among Finnish prisoners. Soc Psychiatry Psychiatr Epidemiol. 2012;47(5): 835-42

31. Jones GY, Hoffmann NG. Alcohol dependence: international policy implications for prison populations. Substance Abuse Treatment Prevention Policy. 2006;1:33.

32. Fotiadou M, Livaditis M, Manou I, Kaniotou E, Samakouri M, Tzavaras N, et al. Self-reported substance misuse in Greek male prisoners. Eur Addict Res. 2004;10(2):56-60.

33. Sahajian F, Lamothe P, Fabry J, Vanhems P. Consumption of psychoactive substances among 535 women entering a Lyon prison (France) between June 2004 and December 2008. Revue d'epidemiologie et de sante publique. 2012;60(5):371-81.

34. Graham L, Heller-Murphy S, Aitken L, McAuley A. Alcohol problems in a remand Scottish prisoner population. Int J Prison Health. 2012;8(2):51-9.

35. Newbury-Birch D, Harrison B, Brown N, Kaner E. Sloshed and sentenced: a prevalence study of alcohol use disorders among offenders in the north east of England. Int J Prison Health. 2009;5(4):201-11.

36. Mir J, Kastner S, Priebe S, Konrad N, Strohle A, Mundt AP. Treating substance abuse is not enough: comorbidities in consecutively admitted female prisoners. Addict Behav. 2015:46:25-30.

37. Payne-James JJ, Wall IJ, Bailey C. Patterns of illicit drug use of prisoners in police custody in London, UK. J Clin Forensic Med. 2005;12(4):196-8.

38. Peters RH, Greenbaum PE, Edens JF, Carter CR, Ortiz MM. Prevalence of DSM-IV substance abuse and dependence disorders among prison inmates. Am J Drug Alcohol Abuse. 1998;24(4):573-87.

39. Agbahowe SA, Ohaeri JU, Ogunlesi AO, Osahon R. Prevalence of psychiatric morbidity among convicted inmates in a Nigerian prison community. East Afr Med J. 1998:75(1):19-26.

40. Mendes dos Santos M, Quintana MI, Moreira FG, Taborda JG, Mari Jde J, Andreoli SB. Drug-related disorders and the criminal and clinical background of the prison population of Sao Paulo State, Brazil. PloS one. 2014;9(11):e113066.

41. Mason D, Birmingham L, Grubin D. Substance use in remand prisoners: a consecutive case study. BMJ (Clinical research ed). 1997:315(7099):18-21.

42. Vaeroy $H$. Depression, anxiety, and history of substance abuse among Norwegian inmates in preventive detention: reasons to worry? BMC Psychiatry. 2011;11:40.

43. Rodriguez-Diaz CE, Reece M, Rivera-Alonso B, Laureano-Landron I, Dodge B, Malow RM. Behind the Bars of Paradise: HIV and Substance Use among Incarcerated Populations in Puerto Rico. Journal of the International Association of Physicians in AIDS Care (Chicago, III : 2002). 2011;10(4):266-72.

44. Monras M, Aparicio A, Lopez JA, Pons I. Prevalence of alcohol consumption related disorders in a prison population convicted of crimes against road safety. Actas Espanolas De Psiquiatria. 2011;39(3):163-7.
45. MacAskill S, Parkes T, Brooks O, Graham L, McAuley A, Brown A. Assessment of alcohol problems using AUDIT in a prison setting: more than an 'aye or no' question. BMC Public Health. 2011;11:865.

46. Fazel S, Yoon IA, Hayes AJ. Substance use disorders in prisoners: an updated systematic review and meta-regression analysis in recently incarcerated men and women. Addiction (Abingdon, England). 2017;112(10):1725-39.

47. Fazel S, Bains P, Doll H. Substance abuse and dependence in prisoners: a systematic review. Addiction (Abingdon, England). 2006;101(2):181-91.

48. Robertson G. Correlates of crime among women offenders. Med Sci Law. 1990;30(2):165-74.

49. Plant G, Taylor PJ. Recognition of problem drinking among young adult prisoners. Behav Sci Law. 2012;30(2):140-53.

50. Hammersley R, Forsyth A, Morrison V, Davies JB. The relationship between crime and opioid use. Br J Addict. 1989;84(9):1029-43.

51. Aromaki AS, Lindman RE. Alcohol expectancies in convicted rapists and child molesters. Crim Behaviour Mental Health. 2001;11(2):94-101.

52. Ayano G, Yohannis K, Abraha M, Duko B. The epidemiology of alcohol consumption in Ethiopia: a systematic review and meta-analysis. Substance Abuse Treatment Prevention Policy. 2019;14(1):26.

53. Yitayih Y, Soboka M, Tesfaye E, Abera M, Mamaru A, Adorjan K. Trauma exposure and alcohol use disorder among prisoners in Jimma Zone correctional institution, Southwest Ethiopia: a cross-sectional study. BMC Research Notes. 2019:12(1):748.

54. Olagunju AT, Oluwaniyi SO, Fadipe B, Ogunnubi OP, Oni OD, Aina OF, et al. Mental health services in Nigerian prisons: lessons from a four-year review and the literature. Int J Law Psychiatry. 2018;58:79-86.

55. City population of Ethiopa [cited 2018 19th March]. Available from: https:// www.citypopulation.de/Ethiopia.html.

56. Meta blue weather broadcast [cited 2018 19th March 2018]. Available from: https://www.meteoblue.com/en/weather/forecast/modelclimate/ debrebirhan_ethiopia_3394.

57. Information about debre berhan [cited 2018 19th March]. Available from: https://en.wikipedia.org/wiki/Debre_Berhan.

58. Babor TF, Higgins-Biddle JC, Saunders JB, Monteiro MG. The alcohol use disorders identification test. Guidelines for use in primary health care. Geneva: World Health Organization; 1992.

59. Reinert DF, Allen JP. The alcohol use disorders identification test (AUDIT): a review of recent research. Alcohol Clin Exp Res. 2002;26(2):272-9.

60. Reinert DF, Allen JP. The alcohol use disorders identification test: an update of research findings. Alcohol Clin Exp Res. 2007:31(2):185-99.

61. Fekadu A, Alem A, Hanlon C. Alcohol and drug abuse in Ethiopia: past, present and future. Afr J Drug Alcohol Stud. 2007;6(1):40-53.

62. AlMarri TS, Oei TP, Amir T. Validation of the alcohol use identification test in a prison sample living in the Arabian gulf region. Substance Use Misuse. 2009:44(14):2001-13.

63. Soboka M, Tesfaye M, Feyissa GT, Hanlon C. Alcohol use disorders and associated factors among people living with HIV who are attending services in south West Ethiopia. BMC Res Notes. 2014;7:828

64. Fekadu A, Hanlon C, Gebre-Eyesus E, Agedew M, Solomon H, Teferra S, et al Burden of mental disorders and unmet needs among street homeless people in Addis Ababa, Ethiopia. BMC Med. 2014;12:138.

65. Waja T, Ebrahim J, Yohannis Z, Bedaso A. Prevalence of alcohol use disorders and associated factors among people with epilepsy attending Amanuel mental specialized hospital, Addis Ababa, Ethiopia. Neuropsychiatr Dis Treat. 2016:12:2989-96.

66. Zenebe Y, Negash A, Feyissa G, Krahl W. Alcohol use disorders and its associated factors among psychiatric Outpatients in Jimma University Specialized Hospital, Southwest Ethiopia; 2015.

67. Sanchez-Ramirez DC, Franklin R, Voaklander D. Hazardous alcohol use in 2 countries: a comparison between Alberta, Canada and Queensland, Australia. Journal of preventive medicine and public health $=$. Yebang Uihakhoe chi. 2017:50(5):311-9.

68. Tesfaye G, Derese A, Hambisa MT. Substance Use and Associated Factors among University Students in Ethiopia: A Cross-Sectional Study. J Addiction. 2014;2014:969837

69. Alem A, Kebede D, Kullgren G. The epidemiology of problem drinking in Butajira, Ethiopia. Acta Psychiatr Scand Suppl. 1999;397:77-83.

70. Yazbek JC, Haddad R, Bou Khalil R, Hlais S, Rizk GA, Rohayem J, et al. Prevalence and correlates of alcohol abuse and dependence in Lebanon: results from the Lebanese epidemiologic survey on alcohol (LESA). J Addict Dis. 2014;33(3):221-33. 
71. Birhanu AM, Bisetegn TA, Woldeyohannes SM. High prevalence of substance use and associated factors among high school adolescents in Woreta town, Northwest Ethiopia: multi-domain factor analysis. BMC Public Health. 2014; 14:1186.

72. Thapa P, Mishra SR, Pandey AR, Belbase P, Acharya C, Bista B, et al. Prevalence and predictors of alcohol consumption among the squatter of Kathmandu Valley. J Nepal Health Res Counc. 2016;14(32):18-26.

\section{Publisher's Note}

Springer Nature remains neutral with regard to jurisdictional claims in published maps and institutional affiliations.

Ready to submit your research? Choose BMC and benefit from:

- fast, convenient online submission

- thorough peer review by experienced researchers in your field

- rapid publication on acceptance

- support for research data, including large and complex data types

- gold Open Access which fosters wider collaboration and increased citations

- maximum visibility for your research: over $100 \mathrm{M}$ website views per year

At $B M C$, research is always in progress.

Learn more biomedcentral.com/submissions 